\title{
The Importance of Controlling $\mathrm{P}_{\mathrm{aCO}}$ Throughout Long-Term Noninvasive Ventilation
}

\author{
Tomomasa Tsuboi MD PhD, Toru Oga MD PhD, Kensuke Sumi MD PhD, \\ Kazuko Machida MD, Motoharu Ohi MD PhD, and Kazuo Chin MD PhD
}

\begin{abstract}
BACKGROUND: The significance of changes in $\mathrm{P}_{\mathrm{aCO}_{2}}$ during long-term noninvasive ventilation (NIV) on prognosis remains unclear. We aimed to clarify whether stabilizing $P_{a_{1} O_{2}}$ during NIV had a favorable prognostic effect. METHODS: Data from 190 subjects with restrictive thoracic disease and who received long-term NIV were studied retrospectively. The annual change in $\mathbf{P}_{\mathrm{aCO}}$ during NIV was determined using a simple linear regression method for each subject who had at least 4 6-month intervals of $\mathbf{P}_{\mathrm{aCO}}$ data. Annual changes in $\mathbf{P}_{\mathrm{aCO}}$ during long-term NIV and possible confounders were analyzed with discontinuation of long-term NIV as the main outcome. RESULTS: One hundred and twenty-five subjects who had $>4$ 6-month intervals of $\mathrm{P}_{\mathrm{aCO}_{2}}$ data were included in the study. $\mathrm{P}_{\mathrm{aCO}}$ during long-term NIV decreased in 41 subjects (group $1 ;<0 \mathrm{~mm} \mathrm{Hg} / \mathrm{y}$ ), increased slightly in 42 subjects (group 2; between 0 and $1.85 \mathrm{~mm} \mathrm{Hg} / \mathrm{y}$ ), and increased significantly in 42 subjects (group 3; $>1.85 \mathrm{~mm} \mathrm{Hg} / \mathrm{y}$ ). Smaller annual changes in $\mathrm{P}_{\mathrm{aCO}}(P<.001$ ) and a control ventilator mode $(P=.008)$ were associated with a significantly higher probability of continuing NIV, compared with decreased $\mathrm{P}_{\mathrm{aCO}_{2}}$ 3-6 months after the start of long-term NIV $(P=.11)$. The $10-y$ probability of continuing NIV was $69 \%$ in group $1,39 \%$ in group 2 , and $12 \%$ in group 3. CONCLUSIONS: A decrease in the annual change of $\mathrm{P}_{\mathrm{aCO}}$ during long-term NIV was shown to be a significantly prognostically favorable factor. Efforts to reduce $\mathrm{P}_{\mathrm{aCO}}$ should be made if $\mathbf{P}_{\mathrm{aCO}}$ increases at a greater rate during long-term NIV. Key Words: chronic respiratory failure; hypercapnia; home mechanical ventilation; noninvasive ventilation; $P_{\mathrm{CO}_{2}}$; restrictive thoracic disease. [Respir Care 2014;59(11):1671-1678. (c) 2014 Daedalus Enterprises]
\end{abstract}

\section{Introduction}

Persistent $\mathrm{CO}_{2}$ retention in subjects with chronic respiratory failure may reflect an adaptive process that allows a lower level of alveolar ventilation, thus unburdening the respiratory muscles and reducing breathlessness, particularly when long-term oxygen therapy is prescribed. ${ }^{1,2}$ This compensatory process may demonstrate the wisdom of nature ${ }^{2}$; however, ventilatory support, such as noninvasive

\footnotetext{
Drs Tsuboi and Sumi are affiliated with the Department of Respiratory Medicine, National Hospital Organization Minami-Kyoto Hospital, Kyoto; Drs Oga and Chin are affiliated with the Department of Respiratory Care and Sleep Control Medicine, Kyoto University Graduate School of Medicine, Kyoto; Dr Machida is affiliated with the Department of Respiratory Medicine, National Tokyo Hospital, Tokyo; and Dr Ohi is affiliated with the Sleep Medical Centre, Osaka Kaisei Hospital, Osaka, Japan.
}

The authors have disclosed no potential conflicts of interest. ventilation (NIV), should be applied if hypercapnic ventilatory failure develops despite this compensation..$^{3-9}$ Over the last 2 decades, domiciliary NIV has been widely used to treat subjects with chronic hypercapnic respiratory failure. ${ }^{10-16}$ Improved daytime $\mathrm{P}_{\mathrm{aCO}_{2}}$ after the initiation of NIV has been correlated with a change in $\mathrm{P}_{\mathrm{aCO}_{2}}$ while receiving nighttime $\mathrm{NIV}, 6,17$ and the most important mechanism underlying the long-term reduction in daytime $\mathrm{P}_{\mathrm{aCO}}$ is an augmented ventilatory response to $\mathrm{CO}_{2} \cdot{ }^{3-5} \mathrm{Ar}-$ terial blood gases (ABGs) stabilize a few months after NIV initiation, and are sustained for many years in sub-

\footnotetext{
Correspondence: Tomomasa Tsuboi MD PhD, Department of Respiratory Medicine. National Hospital Organization Minami-Kyoto Hospital, 11 Naka-Ashihara, Joyo City, Kyoto 610-0113, Japan. E-mail: tomomasa@kuhp.kyoto-u.ac.jp.
}

DOI: $10.4187 /$ respcare. 02829 


\section{Controlling $\mathrm{P}_{\mathrm{aCO}_{2}}$ During Long-Term NIV}

jects with both $\mathrm{COPD}^{10,18}$ and restrictive thoracic disease. ${ }^{10,12,13,19,20}$

We previously showed that the average $\mathrm{P}_{\mathrm{aCO}}$ of subjects breathing spontaneously decreases rapidly within several weeks of NIV, and thereafter increases gradually throughout long-term NIV. 18,20 We hypothesized that the adaptive mechanism that permits chronic hypercapnia occurs even in subjects receiving long-term NIV. In this study, we retrospectively reviewed $\mathrm{P}_{\mathrm{aCO}}$ data sampled at 6-month intervals and at clinically stable times for $>2 \mathrm{y}$, and calculated the rate at which $\mathrm{P}_{\mathrm{aCO}}$ changed in each subject.

Generally in nature, adaptations occur during disadvantageous situations. Therefore, we hypothesized that subjects with a greater annual change in $\mathrm{P}_{\mathrm{aCO}}$ would have lower continuation rates of NIV than those with a more stable $\mathrm{P}_{\mathrm{aCO}}$. Thus, we aimed to clarify which pattern of $\mathrm{P}_{\mathrm{aCO}_{2}}$ change during long-term NIV would be suitable for continued use of NIV.

\section{Methods}

\section{Subjects}

All subjects with restrictive thoracic disease who had begun NIV at the National Hospital Organization MinamiKyoto Hospital (Kyoto, Japan), the National Tokyo Hospital (Tokyo, Japan), or the Kyoto University Hospital (Kyoto, Japan), from June 15, 1990 to August 2, 2007, were included in this study. This same subject cohort was assessed in our previous studies. ${ }^{16,20}$ All subjects had chronic hypercapnic respiratory failure. The criteria to initiate NIV were based on medical symptoms with lasting diurnal hypercapnia $\left(\mathrm{P}_{\mathrm{aCO}_{2}}>45 \mathrm{~mm} \mathrm{Hg}\right)$ and/or nighttime hypoventilation and/or clinical instability with frequent hospitalizations. Subjects with other diseases such as neuromuscular disorders, obesity hypoventilation syndrome, bronchiectasis, or COPD were excluded. The subjects were followed up to November 30, 2007.

This study was performed in the Department of Respiratory Medicine, National Hospital Organization MinamiKyoto Hospital, Kyoto; the Department of Respiratory Medicine, National Tokyo Hospital, Tokyo; and the Department of Respiratory Care and Sleep Control Medicine, Kyoto University Graduate School of Medicine, Kyoto, Japan. This study was approved by the ethics committee of Kyoto University. According to the advice of the ethics committee of Kyoto University, the study procedure was disclosed on our institution website, and all questions have been answered.

\section{Measurements}

Data on age at the initiation of NIV, gender, body mass index, preexisting comorbidities (Charlson index), existence of lung lesions, vital capacity (percentage of pre-

\section{QUICK LOOK}

\section{Current knowledge}

Persistent hypercapnia in chronic respiratory failure results in adaptation and a reduction in the required minute ventilation, reducing the work of breathing and dyspnea. Noninvasive ventilation (NIV) has been used to reduce daytime hypercapnia and improve comfort in patients with chronic lung disease.

\section{What this paper contributes to our knowledge}

During long-term NIV, a reduction in arterial carbon dioxide over 3-6 months is associated with improved compliance with continued NIV use. In patients with progressive hypercapnia despite NIV, efforts to control arterial carbon dioxide are warranted. dicted), $\mathrm{FEV}_{1}$ over forced vital capacity $\left(\mathrm{FEV}_{1} / \mathrm{FVC}\right)$, length of long-term oxygen therapy before the initiation of NIV, clinical status at the start of NIV (ie, acute or chronic), concurrent usage of long-term oxygen therapy after the initiation of NIV, ventilator mode (assisted or controlled mode), inspiratory positive airway pressure, expiratory positive airway pressure, pressure support level (inspiratory positive airway pressure - expiratory positive airway pressure), breathing frequency, $\mathrm{P}_{\mathrm{aCO}_{2}}$ after 3-6 months of NIV, and annual changes in $\mathrm{P}_{\mathrm{aCO}}$ during long-term NIV were all surveyed and assessed to clarify the risk factors.

Data on daytime 6-month intervals of ABGs were gathered from 12 months before the initiation of NIV to the observation end point, if obtainable. ABGs were obtained primarily from 9:00 AM to 1:00 PM, with the subject in the supine position and spontaneously breathing either room air or prescribed oxygen. ABGs were sampled in subjects who were in a stable situation without exacerbation.

All data on the medical course of the subjects were gathered from the medical records.

\section{Clinical Procedure for Initiating Long-Term NIV and Follow-Up}

The detailed procedure for initiating long-term NIV has been described elsewhere. ${ }^{16}$ On initiation of NIV, volume preset ventilators were applied with either custom-made nasal masks ${ }^{21}$ or commercial interfaces. Pressure preset ventilators using bi-level positive airway pressure appliances were utilized with commercial masks. Oxygen was supplemented to keep an arterial oxygen saturation $>95 \%$ during daytime NIV and $>90 \%$ during nighttime NIV. 


\section{Controlling $\mathrm{P}_{\mathrm{aCO}_{2}}$ During Long-Term NIV}

During follow-up, all subjects who were on long-term NIV and/or long-term oxygen therapy had to visit an outpatient clinic once a month, as this is compulsory in Japan. Chest $\mathrm{x}$-rays and $\mathrm{ABG}$ analyses were routinely carried out every 3-6 months.

\section{Statistical Analysis}

The change in $\mathrm{P}_{\mathrm{aCO}}$ during NIV was determined using a simple linear regression method for each subject who had at least 4 6-month intervals of $\mathrm{P}_{\mathrm{aCO}}$ data from 6 to 96 months after the start of long-term NIV. The subjects were divided into 3 groups using tertiles of the distribution of the changes in $\mathrm{P}_{\mathrm{aCO}_{2}}$ (group $1,<0 \mathrm{~mm} \mathrm{Hg} / \mathrm{y}, n=41$; group 2, from 0 to $1.85 \mathrm{~mm} \mathrm{Hg} / \mathrm{y}, n=42$; group 3, $>1.85 \mathrm{~mm} \mathrm{Hg} / \mathrm{y}, n=42$ ).

Means \pm SD were used for subject features and ventilator settings. One-way factorial analysis of variance and post hoc analysis (Scheffé test) were employed for continuous variables, chi-square tests were used, and the $2 \times 3$ contingency table for categorical variables was employed to evaluate differences in subject features among the 3 groups. Continuance of long-term NIV relative to risk factors, including the annual change in $\mathrm{P}_{\mathrm{aCO}}$, was assessed by univariate Cox proportional hazards regression analysis. Thereafter, continuance was evaluated using multivariate analysis with only significant risk factors $(P<.05)$ in univariate analysis. Continuance of long-term NIV was also estimated by Kaplan-Meier analysis (log-rank test). To assess differences in $\mathrm{P}_{\mathrm{aCO}}$ over time among the 3 groups, repeated-measures analysis of variance and post hoc analysis (Scheffé test) were applied. One-way factorial analysis of variance was used to assess differences in $\mathrm{P}_{\mathrm{aCO}_{2}}$ at the same time points among the groups.

\section{Results}

\section{Subject Characteristics}

There were 190 subjects who were on NIV for $>2$ years and were available for follow-up. Two subjects ceased NIV within 2 y due to recovery from hypercapnic respiratory failure. Twenty-one subjects died within 2 y of NIV. Twenty-five subjects were on NIV for $<2$ y but were still on NIV at the final follow-up time point (November 30,2007$)$. Seventeen subjects continued NIV $>2$ y but had $<4$ 6-month intervals of $\mathrm{P}_{\mathrm{aCO}_{2}}$ data. Thus, 125 subjects were available for the final analysis (Fig. 1).

Of the 125 subjects, 119 were post-tuberculosis, 4 had kyphoscoliosis, 1 was post-hemothorax, and 1 had pneumoconiosis. Almost all post-tuberculosis subjects with pulmonary lesions received surgical treatment such as thoracoplasty and/or artificial pneumothorax and/or lobectomy.

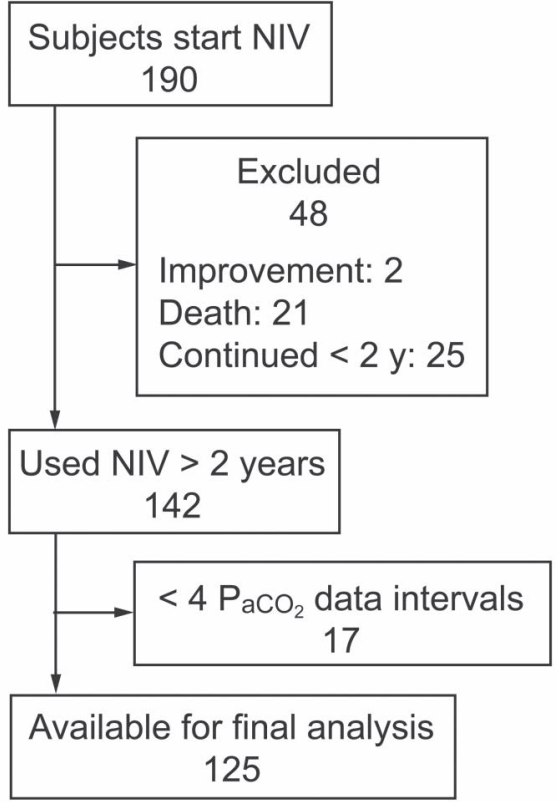

Fig. 1. Of the 190 subjects available for follow-up, 2 discontinued noninvasive ventilation (NIV) within 2 y due to improvement, 21 died within 2 y of beginning NIV, 25 used NIV $<2$ y, and 17 continued NIV $>2$ y but had $<46$-month intervals of $\mathrm{P}_{\mathrm{aCO}_{2}}$ data. Thus, 125 subjects were available for the final analysis.

Post-tuberculosis subjects without pulmonary lesions were diagnosed as having Pott disease.

Of 125 subjects, 62 discontinued long-term NIV. Fortyeight subjects died during long-term NIV, 7 of whom did not receive NIV in the last few days (mostly due to delirium) and received only oxygen therapy. Two subjects received endotracheal invasive ventilation and died with severe exacerbations. Twelve subjects were switched to tracheostomy positive-pressure ventilation due to disease progression, 10 of whom died during long-term tracheostomy positive-pressure ventilation, and 2 continued longterm tracheostomy positive-pressure ventilation until November 30, 2007.

Subject characteristics relative to their annual changes in $\mathrm{P}_{\mathrm{aCO}_{2}}$ are shown in Table 1. On the whole, subjects were characterized by serious restrictive ventilatory failure, crucial hypercapnia, slight malnutrition, and unstable clinical status. Some subjects had a mild obstructive ventilatory defect; however, their chest x-rays and/or chest computed tomographs did not indicate typical emphysema. More subjects in group 1 had no pulmonary lesions compared with groups 2 and 3. Among subjects using bi-level positive airway pressure devices, the expiratory positive airway pressure values were slightly lower in the subjects in group 3 compared with those in group 1 . For inspiratory positive airway pressure and pressure support level, there was no statistical difference between the 3 groups. After 
Table 1. Subject Characteristics at the Beginning of Long-Term Noninvasive Ventilation

\begin{tabular}{|c|c|c|c|c|}
\hline \multirow[b]{2}{*}{ Characteristics } & \multicolumn{3}{|c|}{ Rate of Change of $\mathrm{P}_{\mathrm{aCO}}$} & \multirow[b]{2}{*}{$P$} \\
\hline & $\begin{array}{l}\text { Group } 1 \\
(<0 \mathrm{~mm} \mathrm{Hg} / \mathrm{y} \\
\mathrm{n}=41)\end{array}$ & $\begin{array}{c}\text { Group } 2 \\
(0-1.85 \mathrm{~mm} \mathrm{Hg} / \mathrm{y} \\
n=42)\end{array}$ & $\begin{array}{c}\text { Group 3 } \\
(>1.85(\mathrm{~mm} \mathrm{Hg} / \mathrm{y} \\
n=42)\end{array}$ & \\
\hline Age (y) & $65.4 \pm 12.1$ & $67.3 \pm 6.3$ & $67.8 \pm 7.4$ & .45 \\
\hline Gender (female/male) & $25 / 16$ & $16 / 26$ & $18 / 24$ & .09 \\
\hline BMI $\left(\mathrm{kg} / \mathrm{m}^{2}\right)$ & $19.5 \pm 3.7$ & $19.3 \pm 3.4$ & $17.7 \pm 3.6$ & .06 \\
\hline Charlson comorbidity index & $0.98 \pm 1.15$ & $0.90 \pm 1.16$ & $1.07 \pm 1.07$ & .79 \\
\hline Predicted VC (\%) & $31.5 \pm 7.2$ & $31.9 \pm 8.0$ & $30.3 \pm 9.0$ & .67 \\
\hline $\mathrm{FEV}_{1} / \mathrm{FVC}(\%)$ & $75.0 \pm 14.0$ & $67.5 \pm 13.6$ & $77.6 \pm 18.7 \dagger$ & .02 \\
\hline Pulmonary lesions $( \pm)$ & $32 / 9$ & $40 / 2 *$ & $41 / 1 *$ & .005 \\
\hline Annual hospitalization rate due to respiratory deterioration before NIV & $1.37 \pm 1.07$ & $1.29 \pm 0.77$ & $1.69 \pm 1.12$ & .10 \\
\hline Clinical status (acute/chronic) & $12 / 29$ & $22 / 20$ & $17 / 25$ & .10 \\
\hline Duration of LTOT before NIV (y) & $5.8 \pm 4.5$ & $5.8 \pm 4.5$ & $4.6 \pm 4.1$ & .37 \\
\hline Use of LTOT after NIV (+/-) & $39 / 2$ & $41 / 1$ & $41 / 1$ & .77 \\
\hline Oxygen supply during spontaneous breathing (L/min) & $1.3 \pm 0.6$ & $1.0 \pm 0.5$ & $1.3 \pm 0.7$ & .12 \\
\hline Ventilator mode (assist/control) & $14 / 27$ & $15 / 27$ & $13 / 29$ & .89 \\
\hline BPAP & $n=34$ & $n=31$ & $n=32$ & \\
\hline IPAP $\left(\mathrm{cm} \mathrm{H}_{2} \mathrm{O}\right)$ & $15.9 \pm 3.9$ & $16.0 \pm 3.9$ & $15.2 \pm 4.7$ & .69 \\
\hline $\mathrm{EPAP}\left(\mathrm{cm} \mathrm{H}_{2} \mathrm{O}\right)$ & $4.2 \pm 0.9$ & $3.6 \pm 1.2$ & $3.1 \pm 1.4^{*}$ & $<.001$ \\
\hline PS $\left(\mathrm{cm} \mathrm{H}_{2} \mathrm{O}\right)$ & $11.8 \pm 3.8$ & $12.4 \pm 3.9$ & $12.1 \pm 4.9$ & .81 \\
\hline Breathing frequency (breaths/min) & $21.3 \pm 4.3$ & $21.6 \pm 3.6$ & $22.4 \pm 4.4$ & .54 \\
\hline Volume preset & $n=7$ & $n=11$ & $n=10$ & \\
\hline Tidal volume (mL) & $538 \pm 148$ & $550 \pm 86$ & $534 \pm 123$ & .95 \\
\hline Breathing frequency (breaths/min) & $23.3 \pm 5.1$ & $24.1 \pm 4.7$ & $24.9 \pm 5.0$ & .8 \\
\hline Oxygen supply during NIV (L/min) & $1.8 \pm 0.9$ & $1.5 \pm 0.8$ & $1.6 \pm 0.8$ & .27 \\
\hline ABGs 3-6 mo after starting long-term NIV & $n=39$ & $n=41$ & $n=37$ & \\
\hline $\mathrm{pH}$ & $7.38 \pm 0.03$ & $7.38 \pm 0.03$ & $7.38 \pm 0.04$ & $>.99$ \\
\hline $\mathrm{P}_{\mathrm{aO}_{2}}(\mathrm{~mm} \mathrm{Hg})$ & $84.9 \pm 15.4$ & $83.9 \pm 17.5$ & $84.3 \pm 17.1$ & .97 \\
\hline $\mathrm{P}_{\mathrm{aCO}_{2}}(\mathrm{~mm} \mathrm{Hg})$ & $59.0 \pm 8.0$ & $60.2 \pm 9.3$ & $61.4 \pm 8.9$ & .50 \\
\hline $\mathrm{HCO}_{3}^{-}(\mathrm{mmol} / \mathrm{L})$ & $33.7 \pm 3.6$ & $34.2 \pm 5.4$ & $35.4 \pm 3.9$ & .27 \\
\hline $\begin{array}{l}\text { Values are given as mean } \pm \mathrm{SD} \text {. } \\
* P<.05 \text { (compared with group } 1) \\
\dagger P<.05 \text { (compared to group } 2 \text { ). } \\
\mathrm{BMI}=\text { body mass index } \\
\mathrm{VC}=\text { vital capacity } \\
\mathrm{NIV}=\text { noninvasive ventilation }\end{array}$ & $\begin{array}{l}\text { LTOT }=\text { long-term o } \\
\text { BPAP }=\text { bi-level pos } \\
\text { IPAP }=\text { inspiratory } \mathrm{p} \\
\text { EPAP }=\text { expiratory } \mathrm{p} \\
\mathrm{PS}=\text { pressure suppo } \\
\mathrm{ABGs}=\text { arterial bloc }\end{array}$ & $\begin{array}{l}\text { gen therapy } \\
\text { ve airway pressure } \\
\text { itive airway pressure } \\
\text { itive airway pressure } \\
\text { level } \\
\text { gas analyses }\end{array}$ & & \\
\hline
\end{tabular}

3-6 months of NIV, there was no significant difference in $\mathrm{P}_{\mathrm{aCO}_{2}}$ values among the 3 groups.

\section{The Annual Change in $\mathrm{P}_{\mathrm{aCO}_{2}}$ During Long-Term NIV}

The distribution of the annual changes in $\mathrm{P}_{\mathrm{aCO}_{2}}$ is shown in Figure 2 and the 3 typical $\mathrm{P}_{\mathrm{aCO}_{2}}$ patterns are presented in Figure 3. In group 1, the $\mathrm{P}_{\mathrm{aCO}_{2}}$ rate decreased throughout long-term NIV. In group $2, \mathrm{P}_{\mathrm{aCO}_{2}}$ increased slightly during long-term NIV. In group 3, $\mathrm{P}_{\mathrm{aCO}_{2}}$ increased greatly during long-term NIV.

\section{Time Course of $\mathrm{PaCO}_{2}$ Before and After NIV in the 3 Groups}

An analysis of the $\mathrm{P}_{\mathrm{aCO}}$ time course in the 3 groups is shown in Figure 4. There was a significant difference in the

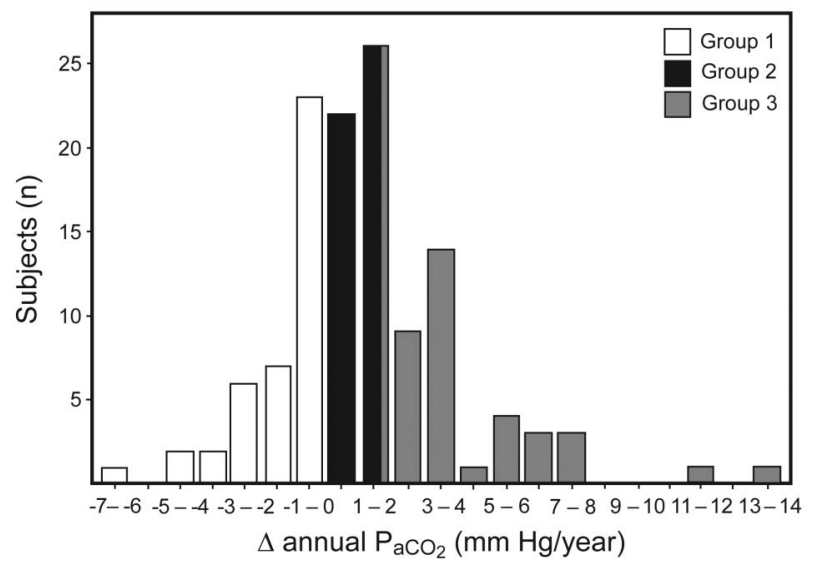

Fig. 2. The distribution of annual $\Delta$ in $\mathrm{P}_{\mathrm{acO}}$. A total of 125 subjects were divided into three groups based on their annual $\Delta \mathrm{P}_{\mathrm{aCO}_{2}}$. Group 1 had $\Delta \mathrm{P}_{\mathrm{aCO}_{2}}<0 \mathrm{~mm} \mathrm{Hg} / \mathrm{y}(n=41)$; group 2 had $\Delta \mathrm{P}_{\mathrm{aCO}_{2}} 0-1.85 \mathrm{~mm}$ $\mathrm{Hg} / \mathrm{y}(n=42) ;$ and group 3 had $\Delta \mathrm{P}_{\mathrm{acO}_{2}}>1.85 \mathrm{~mm} \mathrm{Hg} / \mathrm{y}(n=42)$. 

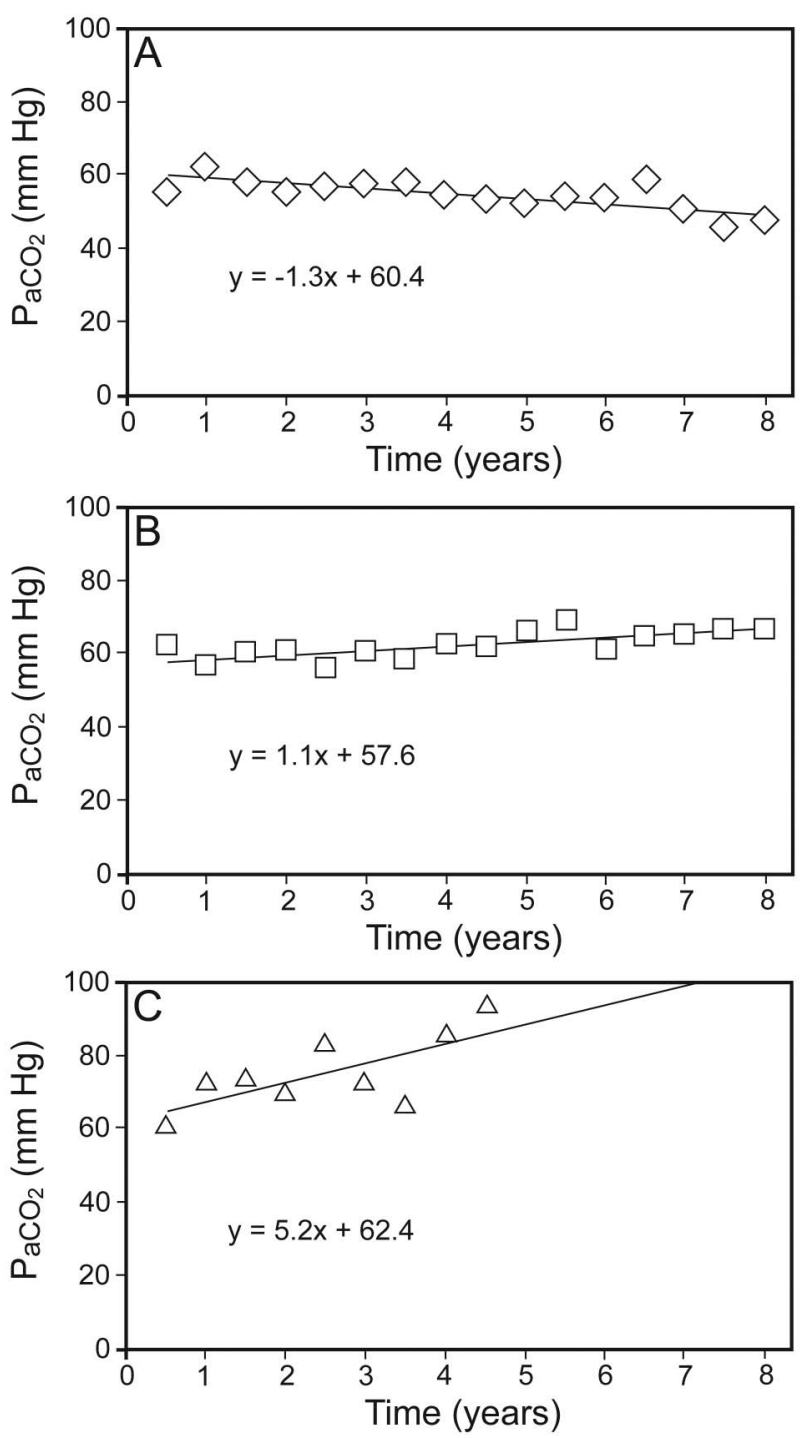

Fig. 3. Three representative patterns of $\mathrm{P}_{a C O}$ changes during longterm noninvasive ventilation (NIV). A: $\mathrm{P}_{\mathrm{aCO}_{2}}$ decreased in the subjects from group 1. $\mathrm{B}: \mathrm{P}_{\mathrm{aCO}_{2}}$ increased slowly in group 2. C: $\mathrm{P}_{\mathrm{aCO}}$ increased rapidly in group 3 .

$\mathrm{P}_{\mathrm{aCO}_{2}}$ time course among the 3 groups $(P=.013)$. In the post hoc analysis, significant differences were observed between groups 1 and $2(P<.001)$, groups 1 and $3(P<.001)$, and groups 2 and $3(P<.001)$.

There were no significant differences in $\mathrm{P}_{\mathrm{aCO}}$ from the 12th month before NIV was initiated to the 24th month after the start of NIV in the 3 groups. From the 30th to the 98th month of long-term NIV, there were significant differences in $\mathrm{P}_{\mathrm{aCO}_{2}}$ at the same time points among the 3 groups (Fig. 4).

\section{Comparison of the Continuation Rate of Long-Term NIV}

In the univariate analysis, being female, of a younger age at the beginning of NIV, having no parenchymal pul-

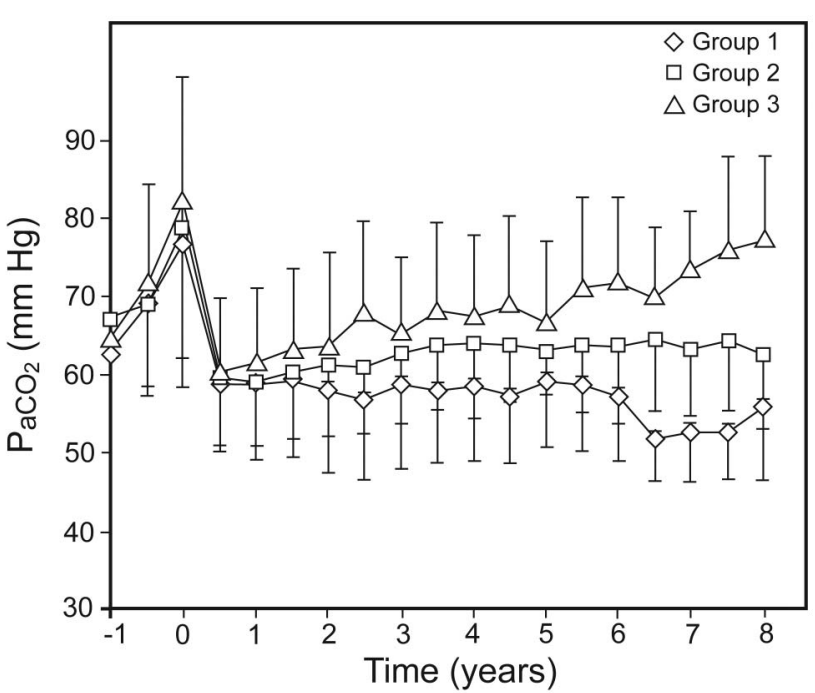

Fig. 4. The $\mathrm{P}_{\mathrm{aCO}}$ time course during long-term noninvasive ventilation (NIV). A comparison of the subjects grouped according to their annual change in $\mathrm{P}_{\mathrm{acO}}$ is shown. Data are presented as mean $\pm \mathrm{SD}$. There was a significant difference in $\mathrm{P}_{\mathrm{acO}}$ over time among the three groups $(P=.013)$. Post hoc analysis showed significant differences between groups. Group 3 had $P<.001$ compared with group 1 and $P<.001$ compared with group 2; group 2 had $P<.001$ compared with group 1 .

monary lesions, a controlled mode, relatively low $\mathrm{P}_{\mathrm{aCO}_{2}}$ levels after 3-6 months of NIV, and lower annual changes in $\mathrm{P}_{\mathrm{aCO}}$ during long-term NIV were all significantly associated with higher continuation rates of NIV (Table 2). Ventilator settings such as inspiratory positive airway pressure, expiratory positive airway pressure, pressure support level, and breathing frequency appeared to have no bearing on the continuation rates of NIV.

Multivariate analysis showed that lower annual changes in $\mathrm{P}_{\mathrm{aCO}_{2}}$ during long-term NIV $(P<.001)$ and controlled ventilation $(P=.008)$ were both significantly related to higher continuation rates of NIV (Table 3 ). There was no statistical difference in continuation rates between groups 1 and $2(P=.89)$.

Results of the Kaplan-Meier analysis revealed significantly enhanced continuance of long-term NIV in subjects with lower annual changes in $\mathrm{P}_{\mathrm{aCO}_{2}}(P<.001$, Fig. 5). The 5- and 10-y probabilities of continuing NIV were, respectively, $75.2 \%$ and $69.0 \%$ for group $1,79.9 \%$ and $38.9 \%$ for group 2, and $58.2 \%$ and $11.7 \%$ for group 3 .

\section{Discussion}

This study showed that, after the initiation of long-term $\mathrm{NIV}, \mathrm{P}_{\mathrm{aCO}}$ decreased gradually in one third of subjects, increased slowly in one third of subjects, and increased greatly in one third of subjects. Those subjects with smaller 


\section{Controlling $\mathrm{P}_{\mathrm{aCO}_{2}}$ During Long-Term NIV}

Table 3. Comparisons of Continuation Rates of Long-Term NIV by Several Risk Factors Including Annual Changes in $\mathrm{P}_{\mathrm{aCO}}\left(\mathrm{Multivariate}_{2}\right.$ Modality Model)

\begin{tabular}{|c|c|c|c|c|}
\hline Variable & Category & $n$ & $\begin{array}{l}\text { Hazard Ratio } \\
\quad(95 \% \mathrm{CI})\end{array}$ & $P$ \\
\hline Annual changes in $\mathrm{P}_{\mathrm{aCO}_{2}}(\mathrm{~mm} \mathrm{Hg} / \mathrm{y})$ & & & & $<.001$ \\
\hline Group 1 & $<0$ & 41 & Reference & \\
\hline Group 2 & $0-1.85$ & 42 & $1.06(0.46-2.45)$ & .89 \\
\hline Group 3 & $>1.85$ & 42 & $3.21(1.42-7.26)$ & .005 \\
\hline \multirow[t]{2}{*}{ Ventilator mode } & Control & 83 & Reference & \multirow{2}{*}{.008} \\
\hline & Assist/control & 42 & $2.08(1.21-3.57)$ & \\
\hline 3-6 mo $\mathrm{P}_{\mathrm{aCO}_{2}}(\mathrm{~mm} \mathrm{Hg})$ & $\mathrm{CV}$ & 117 & $1.03(0.99-1.06)$ & .11 \\
\hline \multirow[t]{2}{*}{ Gender } & Female & 59 & Reference & \multirow{2}{*}{.15} \\
\hline & Male & 66 & $1.49(0.86-2.56)$ & \\
\hline Age $(y)$ & $\mathrm{CV}$ & 125 & $1.03(0.99-1.08)$ & .16 \\
\hline \multirow[t]{2}{*}{ Pulmonary lesions } & - & 12 & Reference & \multirow{2}{*}{.62} \\
\hline & + & 113 & $1.59(0.26-10.0)$ & \\
\hline
\end{tabular}

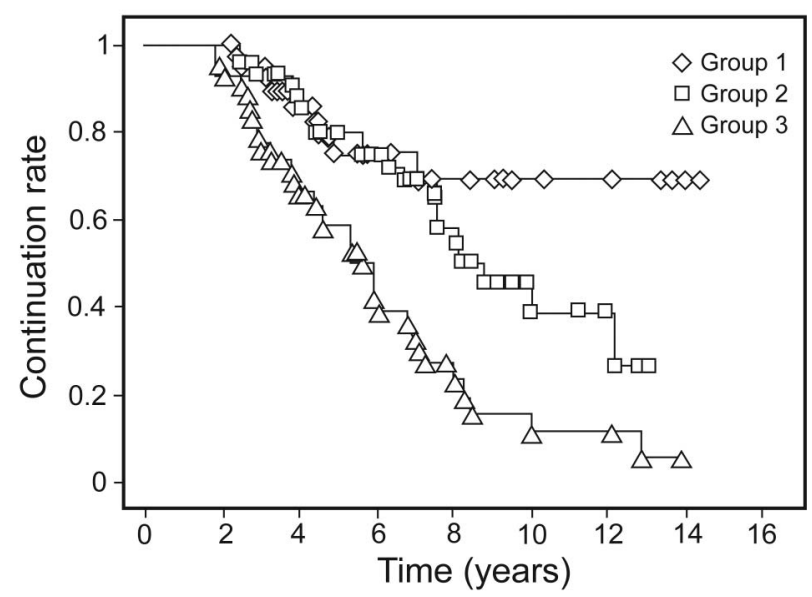

Fig. 5. Kaplan-Meier curves of the continuation rates of long-term noninvasive ventilation (NIV). Subjects were divided into three groups according to their annual changes in $\mathrm{P}_{\mathrm{acO}_{2}}$. Subjects with lower annual changes in $\mathrm{P}_{\mathrm{aCO}}$, had a significantly better prognosis (log-rank test, $P<.001$ ). The 10 -y probability of continuing NIV was $69 \%$ for group $1,39 \%$ for group 2 , and $12 \%$ for group 3 .

mits chronic hypercapnia may have occurred. In general, adaptations develop in difficult situations. Therefore, we hypothesized that the subjects with greater annual changes in $\mathrm{P}_{\mathrm{aCO}}$ were more likely to discontinue NIV than those subjects with a more stable $\mathrm{P}_{\mathrm{aCO}}$.

Hypercapnia is known to be a poor prognostic indicator. ${ }^{9}$ Windisch et $\mathrm{al}^{7}$ proposed that nighttime NIV, with ventilator settings targeted at maximally decreasing $\mathrm{P}_{\mathrm{aCO}_{2}}$, could decrease daytime $\mathrm{P}_{\mathrm{aCO}}$ sufficiently and provide further clinical benefits including a prolonged life. $^{2}$ These reports support the common understanding regarding the advantageous effect of nighttime, high intensity NIV in reducing nighttime, and therefore daytime, $\mathrm{P}_{\mathrm{aCO}_{2}}{ }^{23-25}$ The present study, however, showed that there was no significant difference in $\mathrm{P}_{\mathrm{aCO}_{2}}$ 3-6 months after the start of long-term NIV among the 3 groups. Multivariate analysis indicated that, to predict prognosis, the annual change in $\mathrm{P}_{\mathrm{aCO}_{2}}$ during long-term NIV may be a more useful parameter than $\mathrm{P}_{\mathrm{CCO}_{2}}$ measured a few months after the initiation of long-term NIV. Therefore, we hypothesize that, to improve prognosis, $\mathrm{P}_{\mathrm{aCO}_{2}}$ should not only be reduced as low as possible within a few months of NIV initiation, it should also be stabilized throughout long-term NIV.

During routine clinical care, effort is seldom made to reduce $\mathrm{P}_{\mathrm{aCO}}$, even when $\mathrm{P}_{\mathrm{aCO}}$ increases to considerably high levels during long-term NIV. ${ }^{16,18,20}$ Although it remains unclear whether reducing $\mathrm{P}_{\mathrm{aCO}}$ is effective, we should try to stabilize $\mathrm{P}_{\mathrm{aCO}_{2}}$ throughout long-term NIV by changing the ventilator type, adjusting ventilator settings, increasing the daily time usage of NIV, changing interfaces, and adding nutritional management and pulmonary rehabilitation.

\section{Conclusions}

We found that subjects with smaller annual changes in $\mathrm{P}_{\mathrm{aCO}}$ throughout long-term NIV had significantly higher continuation rates of NIV. Thus, stabilizing $\mathrm{P}_{\mathrm{aCO}}$ throughout long-term NIV may be important for NIV continuance rates. Efforts to reduce $\mathrm{P}_{\mathrm{aCO}_{2}}$ should be made if $\mathrm{P}_{\mathrm{aCO}}$ increases at a greater rate during long-term NIV.

\section{REFERENCES}

1. Barach AL. Hypercapnia in chronic obstructive lung disease: an adaptive response to low-flow oxygen therapy. Chest 1974;66(2): 112-113. 


\section{Controlling $\mathrm{P}_{\mathrm{aCO}_{2}}$ During Long-Term NIV}

2. Petty TL. $\mathrm{CO}_{2}$ can be good for you! Chest 2006;129(2):494; author reply 494-495.

3. Elliott MW, Mulvey DA, Moxham J, Green M, Branthwaite MA. Domiciliary nocturnal nasal intermittent positive pressure ventilation in COPD: mechanisms underlying changes in arterial blood gas tensions. Eur Respir J 1991;4(9):1044-1052.

4. Dellborg C, Olofson J, Hamnegård CH, Skoogh BE, Bake B. Ventilatory response to $\mathrm{CO}_{2}$ re-breathing before and after nocturnal nasal intermittent positive pressure ventilation in patients with chronic alveolar hypoventilation. Respir Med 2000;94(12):1154-1160.

5. Nickol AH, Hart N, Hopkinson NS, Moxham J, Simonds A, Polkey MI. Mechanisms of improvement of respiratory failure in patients with restrictive thoracic disease treated with non-invasive ventilation. Thorax 2005;60(9):754-760.

6. Windisch W, Vogel M, Sorichter S, Hennings E, Bremer H, Hamm $\mathrm{H}$, et al. Normocapnia during nIPPV in chronic hypercapnic COPD reduces subsequent spontaneous $\mathrm{PaCO}_{2}$. Respir Med 2002;96(8): 572-579.

7. Windisch W, Kostiæ S, Dreher M, Virchow JC Jr, Sorichter S. Outcome of patients with stable COPD receiving controlled noninvasive positive pressure ventilation aimed at a maximal reduction of $\mathrm{PaCO}_{2}$. Chest 2005;128(2):657-662.

8. Tuggey JM, Elliott MW. Titration of non-invasive positive pressure ventilation in chronic respiratory failure. Respir Med 2006;100(7): 1262-1269.

9. Elliott MW. Noninvasive ventilation in chronic ventilatory failure due to chronic obstructive pulmonary disease. Eur Respir J 2002; 20(3):511-514.

10. Leger P, Bedicam JM, Cornette A, Reybet-Degat O, Langevin B, Polu JM, et al. Nasal intermittent positive pressure ventilation: longterm follow-up in patients with severe chronic respiratory insufficiency. Chest 1994;105(1):100-105.

11. Simonds AK, Elliott MW. Outcome of domiciliary nasal intermittent positive pressure ventilation in restrictive and obstructive disorders. Thorax 1995;50(6):604-609.

12. Duiverman ML, Bladder G, Meinesz AF, Wijkstra PJ. Home mechanical ventilatory support in patients with restrictive ventilatory disorders: a 48-year experience. Respir Med 2006;100(1):56-65.

13. Brooks D, De Rosie J, Mousseau M, Avendaño M, Goldstein RS. Long-term follow-up of ventilated patients with thoracic restrictive or neuromuscular disease. Can Respir J 2002;9(2):99-106.
14. Gustafson T, Franklin KA, Midgren B, Pehrsson K, Ranstam J, Ström K. Survival of patients with kyphoscoliosis receiving mechanical ventilation or oxygen at home. Chest 2006;130(6):1828-1833.

15. Jäger L, Franklin KA, Midgren B, Löfdahl K, Ström K. Increased survival with mechanical ventilation in posttuberculosis patients with the combination of respiratory failure and chest wall deformity. Chest 2008;133(1):156-160.

16. Tsuboi T, Oga T, Machida K, Chihara Y, Matsumoto H, Niimi A, et al. Importance of ventilator mode in long-term noninvasive positive pressure ventilation. Respir Med 2009;103(12):1854-1861.

17. Meecham Jones DJ, Paul EA, Jones PW, Wedzicha JA. Nasal pressure support ventilation plus oxygen compared with oxygen therapy alone in hypercapnic COPD. Am J Respir Crit Care Med 1995; 152(2):538-544.

18. Tsuboi T, Oga T, Machida K, Sumi K, Oguri S, Sato A, et al. $\mathrm{PaCO}_{2}$ six months after the initiation of long-term noninvasive ventilation in patients with COPD. Int Med 2011;50(6):563-570.

19. Budweiser S, Heinemann F, Fischer W, Dobroschke J, Wild PJ, Pfeifer M. Impact of ventilation parameters and duration of ventilator use on non-invasive home ventilation in restrictive thoracic disorders. Respiration 2006;73(4):488-494.

20. Tsuboi T, Ohi M, Oga T, Machida K, Chihara Y, Harada Y, et al. Importance of the $\mathrm{PaCO}_{2}$ from 3 to 6 months after initiation of long-term non-invasive ventilation. Respir Med 2010;104(12):18501857.

21. Tsuboi T, Ohi M, Kita H, Otsuka N, Hirata H, Noguchi T, et al. The efficacy of a custom-fabricated nasal mask on gas exchange during nasal intermittent positive pressure ventilation. Eur Respir J 1999; 13(1):152-156.

22. Martí S, Pallero M, Ferrer J, Ríos J, Rodríguez E, Morell F, Muñoz $\mathrm{X}$. Predictors of mortality in chest wall disease treated with noninvasive home mechanical ventilation. Respir Med 2010;104(12):18431849.

23. Dreher M, Storre JH, Schmoor C, Windisch W. High-intensity versus low-intensity non-invasive ventilation in patients with stable hypercapnic COPD: a randomised crossover trial. Thorax 2010;65(4): 303-308.

24. Midgren B. Home mechanical ventilation in chest wall disease should aim at full correction of $\mathrm{PaCO}_{2}$. Respir Med 2010;104(12):1765-176.

25. Dreher M, Ekkernkamp E, Walterspacher S, Walker D, Schmoor C, Storre JH, Windisch W. Noninvasive ventilation in COPD: impact of inspiratory pressure levels on sleep quality. Chest 2011;140(4):939945. 